\title{
Effect of multidimensional lifestyle intervention on fitness and adiposity in predominantly migrant preschool children (Ballabeina): cluster randomised controlled trial
}

\author{
(c) $\underset{1}{(1)(8)}$ OPEN ACCESS
}

\author{
J J Puder assistant professor ${ }^{1}$, P Marques-Vidal assistant professor ${ }^{2}, \mathrm{C}_{\text {Schindler }}$ statistician $^{3}$, L \\ Zahner assistant professor ${ }^{4}$, I Niederer research assistant ${ }^{4}$, F Bürgi research assistant ${ }^{4}$, V Ebenegger \\ research assistant ${ }^{5}$, A Nydegger senior lecturer ${ }^{6}$, S Kriemler assistant professor ${ }^{3}$
}

${ }^{1}$ Service of Endocrinology, Diabetes and Metabolism, Centre Hospitalier Universitaire Vaudois, University of Lausanne, Rue du Bugnon 46, 1011 Lausanne, Switzerland; ${ }^{2}$ Institute of Social and Preventive Medicine, Centre Hospitalier Universitaire Vaudois, University of Lausanne, Lausanne; ${ }^{3}$ Swiss Tropical and Public Health Institute, University of Basel, Socinstrasse 57, 4002 Basel; ${ }^{4}$ Institute of Exercise and Health Sciences, University of Basel, Birsstrasse 320b, 4052 Basel; ${ }^{5}$ Institute of Sport Sciences, University of Lausanne, Bâtiments administratifs de Vidy, Route de Chavannes 33, 1015 Lausanne; ${ }^{6}$ Department of Paediatric Gastroenterology and Nutrition, Centre Hospitalier Universitaire Vaudois, University of Lausanne, Lausanne

\begin{abstract}
Objective To test the effect of a multidimensional lifestyle intervention on aerobic fitness and adiposity in predominantly migrant preschool children.

Design Cluster randomised controlled single blinded trial (Ballabeina study) over one school year; randomisation was performed after stratification for linguistic region.
\end{abstract}

Setting 40 preschool classes in areas with a high migrant population in the German and French speaking regions of Switzerland.

Participants 652 of the 727 preschool children had informed consent and were present for baseline measures (mean age 5.1 years (SD 0.7), $72 \%$ migrants of multicultural origins). No children withdrew, but 26 moved away.

Intervention The multidimensional culturally tailored lifestyle intervention included a physical activity programme, lessons on nutrition, media use (use of television and computers), and sleep and adaptation of the built environment of the preschool class. It lasted from August 2008 to June 2009.

Main outcome measures Primary outcomes were aerobic fitness (20 $\mathrm{m}$ shuttle run test) and body mass index (BMI). Secondary outcomes included motor agility, balance, percentage body fat, waist circumference, physical activity, eating habits, media use, sleep, psychological health, and cognitive abilities.

Results Compared with controls, children in the intervention group had an increase in aerobic fitness at the end of the intervention (adjusted mean difference: 0.32 stages ( $95 \%$ confidence interval 0.07 to 0.57 ;
$\mathrm{P}=0.01)$ but no difference in $\mathrm{BMI}\left(-0.07 \mathrm{~kg} / \mathrm{m}^{2},-0.19\right.$ to $\left.0.06 ; \mathrm{P}=0.31\right)$. Relative to controls, children in the intervention group had beneficial effects in motor agility $(-0.54 \mathrm{~s},-0.90$ to $-0.17 ; \mathrm{P}=0.004)$, percentage body fat $(-1.1 \%,-2.0$ to $-0.2 ; P=0.02)$, and waist circumference $(-1.0$ $\mathrm{cm},-1.6$ to $-0.4 ; \mathrm{P}=0.001)$. There were also significant benefits in the intervention group in reported physical activity, media use, and eating habits, but not in the remaining secondary outcomes.

Conclusions A multidimensional intervention increased aerobic fitness and reduced body fat but not BMI in predominantly migrant preschool children.

Trial registration Clinical Trials NCT00674544.

\section{Introduction}

Adiposity and low aerobic fitness in children are associated with a clustering of cardiovascular risk factors. ${ }^{1}$ The high prevalence of childhood obesity ${ }^{2}$ and low fitness ${ }^{34}$ represents a major public health burden. Children with migrant or socially disadvantaged background, or both, are disproportionately affected. ${ }^{56}$ Few prevention programmes exist in these populations, and they are generally less effective..$^{7-9}$ There is therefore a large demand for innovative and effective prevention measures that target this high risk group to avoid the potential widening of inequalities in health.

We had previously carried out a physical activity intervention in schoolchildren aged 7-11 that decreased adiposity and increased aerobic fitness. ${ }^{10}$ Indeed, most prevention studies have 
been performed in schoolchildren, but few of them reported successful results. ${ }^{11}{ }^{12}$ Focusing on younger children has the advantage of tackling a period where the basis for a healthy lifestyle is still being established. In addition, the preschool period (at age 4-6) corresponds to the time of the adiposity rebound, which is thought to be critical for development of obesity. ${ }^{13}$ Little research has been devoted to preschool children, ${ }^{94-20}$ and results of these studies remain controversial regarding their effects on adiposity and fitness.

Existing trials have focused on physical activity or nutrition, but the determinants of obesity and healthy lifestyle behaviours are multiple and inherently complex and interlinked. ${ }^{21}$ The Ballabeina study was designed to focus on several potentially modifiable lifestyle behaviours implicated in the development of childhood obesity or low fitness such as physical activity, nutrition, media use (that is, watching television and playing video and computer games), and sleep. ${ }^{22}{ }^{23}$ In this multidimensional cluster randomised controlled trial we aimed to increase aerobic fitness and reduce body mass index (BMI) in predominantly migrant preschool children of multicultural origin.

\section{Methods}

\section{Study design, setting, and participants}

The Ballabeina study is a cluster randomised controlled trial conducted in 40 randomly selected public preschool classes in areas with a high migrant population from two different sociocultural and linguistic regions in Switzerland. The detailed design of the study protocol has been previously described. ${ }^{24}$ The study was conducted in the German (city of St Gallen; 70 000 inhabitants) and the French (urban surroundings of Lausanne, canton Vaud; 50000 inhabitants) speaking regions of Switzerland during the school year 2008-9. All children in Switzerland attend preschool.

Preschool classes were the unit for randomisation and intervention. Eligibility criteria for the preschool classes included a prevalence of over $40 \%$ of migrant children (defined as at least one parent born outside Switzerland ${ }^{25}$ ) and no participation in any other prevention project.

\section{Randomisation and blinding}

Randomisation of classes $(1: 1)$ was performed separately for the German $(n=20)$ and French $(n=20)$ speaking areas. Classes were randomised with the use of opaque envelopes. For practical reasons, and to minimise contamination, preschool classes affiliated to the same school building were randomised into the same group. The 40 classes were affiliated to 30 schools, but the school had no role during the intervention as all activities were performed at the class level. Recruitment took place between November 2007 and January 2008. Selection and randomisation took place between February and March 2008 and were performed by a person from the school health services who was not involved in the study.

Teachers, parents, and children were informed that the intervention aimed to promote children's health but were unaware of the main objectives of the study. Specially trained researchers measured outcomes and were blinded to group allocation. Contact persons and organisers (IN, FB, VE) were unblinded and were not involved in measuring outcomes. No financial incentives were provided.

\section{Intervention}

The intervention was developed with the help of exercise physiologists, preschool teachers, paediatricians, dietitians, psychologists, and various stakeholders including experts for migrant families. The rationale, pilot studies, focus groups, and intervention methods have been described in detail elsewhere. ${ }^{24}$ The intervention lasted one school year (end of August 2008 to mid-June 2009) and was based on the following four lifestyle behaviours: physical activity, nutrition, media use, and sleep. The study was designed to intervene at the individual (children, teachers, and parents) and environmental (school curriculum and built environment of the preschool class) levels. All intervention classes followed the same curriculum (that is, workshops, lessons, home activities, offers of extracurricular activities, adaption of the built environment). The intervention focused on changes in education, attitudes, and behaviour and on providing social support. To be culturally tailored, we evaluated norms and needs in different pilot studies and focus groups, translated information as needed, kept recommendations simple and short with many pictures, and focused on practical exercises. Trained health promoters intervened on the level of the teachers (workshops, visits with hands on training, assistance in the adaptation of the built environment), parents (events in collaboration with the teachers), and children (physical activity lessons).

Children-Children participated in a physical activity programme consisting of four 45 minute sessions of physical activity a week. The sessions were prepared by an exercise physiologist and aimed to increase aerobic fitness and coordination skills; they were designed to be playful and organised into themes (such as "clown, spiderman"). The sessions took place in or around the preschool classroom and once a week in the gym. Additional sports equipment such as balls or skipping ropes was offered. Health promoters taught one physical activity sessions a week, which was reduced to twice a month after four months. The remaining sessions were provided by the regular preschool teacher. Additionally, there were 22 sessions on healthy nutrition, media use, and sleep. Positive and culturally independent nutritional messages were based on the five recommendations of the Swiss Society of Nutrition ("drink water," "eat fruit and vegetables," "eat regularly," "make clever choices," "turn your screen off when you eat"). ${ }^{27}$ Every other week children received a new funny physical activity or nutrition activity card to take home. These cards were based on the same themes and nutritional recommendations as the sessions and included specific exercises to be done at home. A CD with specific music for most physical activity cards was created to increase pleasure and define the minimal time the activity should be performed. In addition, healthy snacks during recess and healthy treats for anniversaries were promoted and preschool classes exclusively offered their children water and healthy food. In May 2009, a Ballabeina event was organised with games implementing the main messages of the intervention. Stickers that were pasted on a poster in the classroom showed how the programme was advancing. Regardless of consent, participation in the intervention was mandatory for all children. Additional information about the intervention material is provided elsewhere. ${ }^{27} 28$

Teachers - Teachers participated in two workshops before the intervention to learn about the content and the practical aspects of the intervention. During the intervention, they took part in one formal meeting to exchange their experiences and in evenings organised for the parents. All these activities were organised by the health promoters for all teachers of one 
respective linguistic region together. Teachers received the prepared intervention lessons several weeks in advance. For the physical activity sessions, they were supported by the health promoters through hands on training during their visits. Health promoters also assisted in the choices regarding how to adapt the built environment in and around the preschool class.

Parents-Parents participated in three interactive information and discussion evenings about promotion of physical activity, healthy food, limitation of TV use, and importance of sufficient sleep. These were organised by the health promoters in collaboration with the respective preschool teacher. Further support was provided by brochures, the physical activity or nutrition activity cards, and worksheets that children brought home. Information leaflets were provided in 10 different languages, and native speakers of the main foreign languages were available to answer questions. Participation of children in extracurricular activities was also encouraged but not verified.

Environmental factors-Besides curricular changes, the built environment in and around the preschool class was adapted to promote physical activity. Fixed and mobile equipment such as climbing walls, hammocks, balls, cords, or stilts were installed or provided in and around classrooms, including a "movement corner." These adaptations were aimed to promote children's physical activity during recess (playtime or break) as well as unstructured physical activity during school time and were done in coordination with the respective building departments.

Preschool classes were provided with a coloured poster of the "Ballabeina track" to be hung up on a classroom wall. According to the themes of the lessons and cards, stickers were added to allow children and parents to follow progress. Similarly, each class received a large "Ballabeina game" integrating all four lifestyle behaviours that were targeted during the intervention to provide a playful and constant recapitulation of the different parts of the intervention.

\section{Control group}

The control group did not receive any intervention and continued their regular school curriculum, which included one 45 minute physical activity lesson a week in the gym. In the French speaking region there was one additional 45 minute rhythmic lesson a week, corresponding to their regular curriculum. Parents of children in the control group participated in one information and discussion evening.

\section{Objectives and outcomes}

We tested the efficacy of the intervention by comparing participants allocated to the intervention group with those in the control group at the end of the intervention. ${ }^{24}$ Measurements were performed before the intervention (August 2008) and at the end (June 2009). All primary and secondary outcomes were measured less than two weeks apart and are reported at the level of the individual child. Physical fitness outcomes were assessed in the gym and adiposity outcomes and cognitive abilities in a separate room close to the classroom. Specially trained researchers measured all outcomes, and a doctor supervised the tests in the preschool class. Additional details on the prespecified outcomes and pilot studies evaluating the feasibility and test-retest validity of the measures in this population have been previously reported. ${ }^{24}$

\section{Primary outcomes}

Primary outcomes included BMI and aerobic fitness. Body height and weight were measured by standardised procedures. ${ }^{24}$ Aerobic fitness was assessed by the $20 \mathrm{~m}$ shuttle run test, where children run back and forth for $20 \mathrm{~m}$ with an initial running speed of $8.0 \mathrm{~km} / \mathrm{h}$ and a progressive $0.5 \mathrm{~km} / \mathrm{h}$ increase of the running speed every minute. ${ }^{29}$ Results were expressed as stages; one stage corresponding to the running time of one minute. Eight to 10 children took the test at one time, and a researcher assigned to each child checked adequate test procedures. In an unpublished pilot study in this population, test-retest reliability was $r=0.84(\mathrm{n}=20, \mathrm{P}<0.001)$.

\section{Secondary outcomes}

Secondary outcomes included additional measures of adiposity and fitness. ${ }^{24}$ Overweight was defined according to cut offs of the International Obesity Task Force (IOTF). ${ }^{30}$ Bioelectrical impedance analysis was performed with a four polar single frequency device (RJL Systems, Model 101A; Detroit, MI, USA) and percentage body fat calculated with a validated formula for children in this age group. ${ }^{31}$ The sum of four skinfolds (triceps, biceps, subscapular, and suprailiac) was measured in triplicate to the nearest $0.5 \mathrm{~mm}$ with Harpenden calipers (HSK-BI; British Indicators, Burgess Hill, West Sussex, UK). ${ }^{32}$ Waist circumference was measured with a flexible tape midway between the iliac crest and the lowest border of the rib cage. Motor agility (obstacle course) and dynamic balance (balance beam) were tested individually within groups of three to four children. The obstacle course includes the time needed to run from a marking cone to a bench, jumping over the bench ( $36 \mathrm{~cm}$ high, $28 \mathrm{~cm}$ wide), crawling back under this bench, and running back to the marking cone three times in a row as fast as possible. ${ }^{33}$ Dynamic balance included the number of successful steps with the child balancing barefoot on a $3 \mathrm{~m}$ long and $3 \mathrm{~cm}$ wide balance beam. ${ }^{35}$ Static balance was determined on a balance platform (GKS 1000, IMM, Mittweida, Germany) by measuring the displacement (in $\mathrm{mm}$ ) of the centre of pressure in a two dimensional system. ${ }^{36}$

Secondary outcomes also included physical activity measured by accelerometry (MTI/CSA 7164, Actigraph, Shlimar, FL, USA) and reported physical activity, eating habits, media use, sleep duration, quality of life, and cognitive abilities (attention and spatial working memory). ${ }^{24}$ Accelerometers were consistently worn around the hip over five days at baseline and at the end of the intervention (both summertime) and were programmed to save data in 15 second intervals (epochs). To consider data as valid, we needed at least three days of recording (two weekdays and one weekend day) ${ }^{37}$ with a minimum of six hours' registration a day. Sequences of at least 10 minutes of consecutive zero values were considered as "accelerometer not worn" and were removed ${ }^{38}$ Children wore the accelerometers for a mean of 10.8 (SD 1.2) hours a day.

Eating habits were assessed by the parents with a semiqualitative food frequency questionnaire. ${ }^{25}{ }^{39}$ Healthy eating habits were defined according to the five recommendations of the Swiss Society of Nutrition (see above) ${ }^{25}{ }^{27}$ Each recommendation also included two subtopics. For example, the first recommendation ("drink water") included the encouragement of drinking water and the reduction of sweetened drinks. For each topic, we built quarters of responses as the values of the respective topics had different codings. Thereby, binary variables were created (coding 1 for the healthiest quarter versus 0 for the others). The binary variables were further summed to create a general healthy eating score. "Healthy eaters" thus corresponded to the highest quarter of their recommendations. As numbers with the same values were put into the same category, the number of "healthy eaters" does not exactly correspond to $25 \%$. Other lifestyle characteristics - such as reported habitual physical activity to get an idea of physical activity over a more prolonged time 
period, ${ }^{40}$ media use including TV viewing and playing video and computer games, sleep duration, ${ }^{41}$ health related quality of life (PedsQL 4.0), ${ }^{42}$ and sociocultural characteristics-were assessed by a general health questionnaire that was filled in by the parents. "Active children" were defined as those said to be "more" or "much more" active than their peers of the same sex and age. ${ }^{40}$ We determined migrant status of the parents by their country of birth ${ }^{25}$ and educational level as the highest grade of school completed (five levels). Low parental educational level was defined as a maximum of nine years of education (mandatory school years). For descriptive analyses, migrant status and low parental education were divided into three categories (no migrant parent/with low education, one migrant parent/with low education, both migrant parents/with low education). Children were also categorised into two groups according to the language most often spoken at home (native language or French/German). Because of school legislation, we could not obtain any information about income (that is, earning, wages). To test attention, children had to sort 40 cards with familiar pictures into four different boxes,${ }^{43}$ and we assessed sorting time (quantitative dimension) and number of correct cards (qualitative dimension). To test spatial working memory, an increasing number of geometrical forms, which became more and more complex, had to be memorised and then recognised from a new set of figures including colours as distracters. ${ }^{44}$ The health promoters evaluated process of the implementation in the preschool class and at home through parental questionnaires. The only deviation from the protocol was that, on demand of the teachers, only one instead of two formal meetings with the teachers was organised during the intervention.

\section{Statistical methods}

All analyses were performed with Stata version 11.0 (Statacorp, College Station, TX, USA). With an average class size of 18, we assumed that, on average, 13 children a class would participate in both shuttle run tests (because of non-participation, attrition, moving, sickness on the testing day). We calculated that 40 classes would provide $90 \%$ power for detecting a true intervention effect of half a standard deviation between participants at the significance level of 0.05 , provided that the SD of the random class effect does not exceed $25 \%$ of the SD between participants (that is, corresponding to an intraclass correlation of around 0.06 ). We hypothesised a corresponding effect size for change in BMI and shuttle run performance.

Analyses were performed on an intention to treat basis, by using data from individual children but adjusting for clustering of outcomes within preschool classes. Data are described by mean (SD) or percentages. Intervention effects were estimated with mixed linear and logistic regression models, with adjustment for baseline outcomes, age, sex, and sociocultural and linguistic region (German versus French part of Switzerland) as covariates. The effect estimates for the quantitative outcome variables describe the difference between the mean change in the intervention group and the mean change in the control group. The effect estimates for binary outcome variables were obtained from logistic regression models and are presented as odds ratios with $95 \%$ confidence intervals. We also tested whether additional cluster adjustment for "school" influenced the results. Potential modifications of intervention effects by sex or age were tested and were all found to be non-significant. No P value adjustment for parallel comparisons was made because the focus was on effect estimation, and there is considerable correlation between the outcome and the predictor variables considered.

\section{Results \\ Participant flow}

Figures $1 \Downarrow$ and $2 \Downarrow$ show the flow charts of the trial profile. A total of 40 preschool classes ( 727 children) entered the study and were randomly assigned to group (20 in each) after stratification for sociocultural and linguistic region. Informed consent was obtained from 655 children (90\% participation rate), and 652 were examined at baseline. A sample of 342 children received the intervention. None of the 40 preschool classes left the study, and eight children in the intervention group and 18 in the control group had moved away by the end of the year.

\section{Baseline data}

Table 1 shows the characteristics of the children at baseline $\Downarrow$. Of the participating children, $72 \%$ had at least one parent and $48 \%$ had two parents born outside of Switzerland. We noted no differences in baseline characteristics and outcome variables between the intervention and control groups (all $\mathrm{P} \geq 0.2$ ).

\section{Outcomes}

Tables 2 and 3 present data on outcomes $\Downarrow \Downarrow$. There was a significantly higher increase in aerobic fitness in the intervention group than in the control group. The adjusted mean difference versus the control group corresponded to $11 \%$ of the mean baseline values in the $20 \mathrm{~m}$ shuttle run test or to an absolute increase in running distance of $56 \mathrm{~m}$. Although we found no group difference in BMI at follow-up (table 2), children in the intervention group showed reductions in percentage body fat and the sum of four skinfolds and lower increases in waist circumference than control children, with intervention effects being in the order of $5 \%, 10 \%$, and $2 \%$ of the respective mean baseline values. They also showed a more pronounced improvement in motor agility (time to perform an obstacle course) but not in static or dynamic balance. There were also significant beneficial effects of the intervention on reported physical activity, eating habits, and media use. There was no effect on the prevalence of overweight, measured physical activity, sleep duration, cognitive abilities, and quality of life (table 3). Additional cluster adjustment for "school" did not alter the results.

\section{Process evaluation}

Over the course of the study we obtained feedback on the intervention from 20 (out of 20) teachers and 297 (out of 342) parents. Most teachers (95\%) attended both workshops and the informal meeting. Most physical activity and nutrition lessons were implemented as planned (95\% (SD 6\%) for physical activity (corresponds to 3.8 (SD 0.2 ) physical activity lessons a week) and $88 \%$ (14\%) for nutritional lessons (corresponds to 19.3 (SD 3.0) lessons, of the 22 lessons). In 85\% (17/20) of the classes, the built environment in or around the preschool class was adapted. Most (85\%) parents came to at least one of the three information evenings, and over $90 \%$ reported having seen the physical activity and nutrition cards with the home exercises. According to parental report $75 \%$ (220/293) and 80\% (235/293) of the children had carried out the nutrition and physical activity exercises on the cards or worksheets regularly at home, and $89 \%(239 / 270)$ and $92 \%(257 / 281)$ had liked the respective cards. 


\section{Adverse events}

No injuries or other adverse events occurred during physical activity sessions in the intervention classes.

\section{Discussion \\ Main findings}

A multidimensional school based intervention in predominantly migrant preschool children in two socioculturally and linguistically different regions in Switzerland led to improvements in aerobic fitness but no changes in BMI. The intervention included a physical activity programme, lessons on nutrition, media use, and sleep, and adaptation of the built environment of the preschool class. The intervention also led to beneficial effects in percentage body fat, the sum of four skinfolds, waist circumference, and motor agility. Effect sizes were $11 \%$ for aerobic fitness and 5-10\% for body fat. Fitness and body fat are both important health determinants. The observed improvements point to a combined effect of several potentially modifiable determinants, especially as beneficial changes were reported in physical activity, eating habits, and media use.

\section{Strengths and limitations}

A novelty of our study was the focus on young migrant children of multicultural origins in Europe, a population at high risk for development of obesity. ${ }^{6}$ Further strengths are the multidimensional approach, the main focus on adiposity and fitness, the comprehensive assessment, the high participation rate, and the rigorous implementation. The inclusion of sleep as part of a lifestyle intervention represents an innovative concept. According to age, sleep durations of 10-10.5 hours a night have been suggested to protect against obesity. ${ }^{23}{ }^{45}$ Though this intervention had no effect on duration of sleep, sleep at baseline might have been sufficient for most preschool children as only $5 \%$ slept less than 10 hours a night. Based on our results, future intervention should focus specifically on these high risk children. The effect of lifestyle on psychological health and cognitive abilities in young children has been previously debated but not investigated in a randomised design. We therefore included the assessment of those parameters. Neither measure improved, which raises questions regarding their direct link or the need for other approaches. For example, to achieve significant neurocognitive benefits, the physical activity intervention might need to be more intense or contain more tasks that specifically demand both physical and cognitive resources.

A limitation of this study is the use of an indirect measurement of oxygen consumption $\left(\mathrm{VO}_{2}\right)$ to test aerobic fitness. The shuttle run test, however, had good reproducibility in our pilot trial, and laboratory tests would not have been feasible in this epidemiological study. We chose BMI as the primary outcome measure in view of a possible implementation strategy including simple and cost effective measurement tools, and in our pilot studies we had had a high refusal rate for both bioelectrical impedance analysis and skinfold measures. BMI, however, did not change. A more intense intervention within the preschool setting outside of a research project would not be feasible, but more extensive involvement of parents, the community, and policies could be possible. ${ }^{46}$ On the other hand, given the low prevalence of overweight at baseline, perhaps there was no need to lower BMI. In addition, more specific measurements of body fat could be necessary to measure the effect of a physical activity intervention in a general non-obese population, ${ }^{47}$ which is consistent with our own results regarding central and total body fat. Increases in adiposity in the controls during this time period might be explained by the timing of the adiposity rebound.

We found no effect of the intervention on measured physical activity. Despite this finding, increases in physical activity throughout the year are likely to have occurred in view of the improvements in aerobic fitness and motor agility, which were manifest in the absence of any changes in BMI. Furthermore, the lack of effect on measured physical activity might be in part explained by the large variability of physical activity within individuals, ${ }^{48}$ its low measurement precision regarding the extensive use of "gliding activities" on bikes, scooters, or roller skates, ${ }^{49}$ and the fact that the follow-up measurements took place at the end of the school year, when the intervention was diluted by other end of year events. Of particular note is that eight of the 20 control classes had their sports week during their follow-up assessment of physical activity. Generally, the weak to moderate reproducibility of many measures in this young age group $^{24}$ and the lack of power could also explain why some of the secondary outcomes might not have been significantly affected. Despite the achieved effects for many outcomes, our study confirms how hard it is to change behaviour, even in young preschool children. Another limitation is that the study lacks long term assessment of the observed effects. Ideally, this programme should be continued into advancing school years and its long term effects evaluated.

\section{Comparison with other studies}

Previous trials have shown no or limited success when intervening in migrant or socially disadvantaged children. ${ }^{7-9}$ In the current study, the many activities in school and their mandatory nature and cultural adaptations probably played a major role in achieving beneficial effects. ${ }^{50}$

Several randomised controlled trials in preschool children have aimed to reduce BMI or body fat, or both. ${ }^{9}{ }^{14-20}$ Of these, one focused on television viewing ${ }^{15}$ and the others on physical activity with our without a nutritional intervention, but none was multidimensional. Two studies combining physical activity with nutritional interventions showed beneficial effects. ${ }^{16}{ }^{17}$ One was a small, intense physical activity intervention (270 minutes a week) over 14 weeks. ${ }^{16}$ The other, performed in a population with a baseline prevalence of overweight of over $30 \%$, was less intensive but included parents with the help of weekly newsletters and homework assignments that were linked to financial incentives. ${ }^{17}$ Physical activity in our intervention was rather intense, amounted to 180 minutes a week, and was complemented by home exercises, while the weekly physical activity lessons in the control group focused less on endurance. As addressed in previous studies, ${ }^{20}$ high intensity and parental inclusion could be two important factors in achieving an effect on adiposity in this age group and a more multidimensional approach might be favourable. Two previous randomised controlled trials in preschool children have assessed effects on aerobic fitness, but both lack methodological quality and used either a 600 m run or a 10 m shuttle run test. ${ }^{9}{ }^{16}$ Similar to our results, the only other preschool study that used accelerometers did not find an effect of the intervention on physical activity. ${ }^{20}$

\section{Implications and generalisability}

Aerobic fitness predicts reduced morbidity and mortality in adults ${ }^{51-53}$ and is associated with a more beneficial cardiovascular risk profile in children. ${ }^{1054}$ As aerobic fitness in children predicts future physical activity ${ }^{55}$ it might help to sustain achieved intervention effects. Therefore, and in view of a substantial 
decrease in children's fitness of $10 \%$ over the past 20 years, ${ }^{34}$ the improvements in aerobic fitness of $11 \%$ in favour of the intervention group are relevant.

The spread of non-communicable diseases presents a global crisis and particularly affects individuals who are poor, which raises already existing inequalities. ${ }^{56}$ In response to this crisis, a strong focus on primary prevention has been defined as a public health priority, encouraging interventions in young children. ${ }^{56}$ The preschool age is thought to be a critical time for the development of overweight and obesity. ${ }^{13}$ This was also evident in our study, in which the prevalence of overweight, particularly in the control group, started to increase at the end of the study period. The study took place in two socioculturally and linguistically different parts of Switzerland, which reflected the broader situation in Europe including more "northern and southern" cultural regions. This and the multicultural origins of the migrant populations suggest that the intervention would be more universally applicable within Europe. Based on the few successful preschool interventions, ${ }^{16}{ }^{17}$ additional approaches to enhance parental collaboration-such as combining school based interventions with interventions in the health setting and community actions and complementing such programmes with wider environmental and policy intervention — should be further evaluated in future studies.

In conclusion, our approaches to target a multicultural population of preschool children did not change BMI but resulted in improvements in aerobic fitness and body fat, both important health determinants. Currently, some of the Cantonal Health promotion programmes in Switzerland are implementing several modules of the Ballabeina intervention. Further dissemination of this programme could contribute to reduce some aspects of the burden of chronic diseases and of the health inequalities that have arisen as a consequence of social inequities.

We thank Rolf Gaillard, Nelly Pitteloud, Sergio Fanconi, and Fabien Ohl, who helped to make this study possible. We specially thank all the children, their parents, the school teachers, and the respective school health services.

Contributors: JJP and SK designed the study. JJP was the principal investigator and is guarantor. All authors established the methods and questionnaires. IN, FB, VE, and JJP were the main coordinators of the study. IN, FB, VE, LZ, AN, PM-V, and JJP conducted the study. CS and PM-V gave statistical and epidemiological support. JJP wrote the article with the support of SK, PM-V, FB, and IN. JJP obtained the funding, with the assistance of SK and LZ. All authors provided comments on the drafts and have read and approved the final version.

Funding: The study was mainly supported by the Swiss National Science Foundation (grant No 3200B0-116837) and Health Promotion Switzerland (project No 2104). Additional funding was obtained from a research award for interdisciplinary research from the University of Lausanne, a Takeda research award, the Wyeth Foundation for the Health of Children and Adolescents, the Freie Akademische Gesellschaft, and an unrestricted educational grant from Nestlé. The funding sources had no role in the study design, data collection, analysis, interpretation of data, in the writing of the report, and in the decision to submit the article for publication.

Competing interests: All authors have completed the ICMJE uniform disclosure form at www.icmje.org/coi_disclosure.pdf (available on request from the corresponding author) and declare: no support from any organisation for the submitted work; no financial relationships with any organisations that might have an interest in the submitted work in the previous three years; no other relationships or activities that could appear to have influenced the submitted work.
Ethical approval: The study was approved by ethical committees of the cantons involved in the study, and written informed consent was given by a parent or legal representative of each child.

Data sharing: Data about unadjusted changes and their standard deviations are available from the corresponding author.

1 Andersen LB, Sardinha LB, Froberg K, Riddoch CJ, Page AS, Anderssen SA. Fitness, fatness and clustering of cardiovascular risk factors in children from Denmark, Estonia and Portugal: the European Youth Heart Study. Int J Pediatr Obes 2008;3:58-66.

2 Kalies H, Lenz J, von Kries R. Prevalence of overweight and obesity and trends in body mass index in German pre-school children, 1982-1997. Int J Obes Relat Metab Disord 2002;26:1211-7.

3 Tremblay MS, Shields M, Laviolette M, Craig CL, Janssen I, Gorber SC. Fitness of Canadian children and youth: results from the 2007-2009 Canadian Health Measures Survey. Health Rep 2010;21:7-20.

4 Tomkinson G, Olds $\mathrm{T}$. Secular changes in pediatric aerobic fitness test performance: the global picture. Med Sport Sci 2007;50:46-66.

5 Okely AD, Hardy LL, Booth ML, Dobbins TA, Denney-Wilson EA, Yang B. Changes in cardiorespiratory fitness among children and adolescents in Australia: 1997 and 2004. J Sports Sci 2010;28:851-7.

6 Lasserre AM, Chiolero A, Cachat F, Paccaud F, Bovet P. Overweight in Swiss children and associations with children's and parents' characteristics. Obesity (Silver Spring) 2007:15:2912-9.

7 Muckelbauer R, Libuda L, Clausen K, Toschke AM, Reinehr T, Kersting M. Immigrational background affects the effectiveness of a school-based overweight prevention program promoting water consumption. Obesity 2010;18:528-34.

8 Muller MJ, Danielzik S, Pust S. School- and family-based interventions to prevent overweight in children. Proc Nutr Soc 2005;64:249-54.

9 Nemet D, Geva D, Eliakim A. Health promotion intervention in low socioeconomic kindergarten children. J Pediatr 2011;158:796-801.

10 Kriemler S, Zahner L, Schindler C, Meyer U, Hartmann T, Hebestreit H, et al. Effect of school based physical activity programme (KISS) on fitness and adiposity in primary schoolchildren: cluster randomised controlled trial. BMJ 2010;340:c785.

11 Brown T, Summerbell C. Systematic review of school-based interventions that focus on changing dietary intake and physical activity levels to prevent childhood obesity: an update to the obesity guidance produced by the National Institute for Health and Clinical Excellence. Obes Rev 2009;10:110-41.

12 Dobbins M, De Corby K, Robeson P, Husson H, Tirilis D. School-based physical activity programs for promoting physical activity and fitness in children and adolescents aged 6-18. Cochrane Database Syst Rev 2009;1:CD007651.

13 Rolland-Cachera MF, Deheeger M, Maillot M, Bellisle F. Early adiposity rebound: causes and consequences for obesity in children and adults. Int $J$ Obes 2006;30:11-17.

14 Bayer O, von Kries R, Strauss A, Mitschek C, Toschke AM, Hose A, et al. Short- and mid-term effects of a setting based prevention program to reduce obesity risk factors in children: a cluster-randomized trial. Clin Nutr 2009;28:122-8.

15 Dennison BA, Russo TJ, Burdick PA, Jenkins PL. An intervention to reduce television viewing by preschool children. Arch Pediatr Adolesc Med 2004;158:170-6.

16 Eliakim A, Nemet D, Balakirski $Y$, Epstein $Y$. The effects of nutritional-physical activity school-based intervention on fatness and fitness in preschool children. J Pediatr Endocrinol Metab 2007;20:711-8.

17 Fitzgibbon ML, Stolley MR, Schiffer L, Van Horn L, KauferChristoffel K, Dyer A. Two-year follow-up results for Hip-Hop to Health Jr: a randomized controlled trial for overweight prevention in preschool minority children. $J$ Pediatr 2005;146:618-25.

18 Fitzgibbon ML, Stolley MR, Schiffer L, Van Horn L, KauferChristoffel K, Dyer A. Hip-Hop to Health Jr for Latino preschool children. Obesity 2006;14:1616-25.

19 Mo-suwan L, Pongprapai S, Junjana C, Puetpaiboon A. Effects of a controlled trial of a school-based exercise program on the obesity indexes of preschool children. Am J Clin Nutr 1998;68:1006-11

20 Reilly JJ, Kelly L, Montgomery C, Williamson A, Fisher A, McColl JH, et al. Physical activity to prevent obesity in young children: cluster randomised controlled trial. $B M J$ 2006;333:1041.

21 Wilson T, Holt T, Greenhalgh T. Complexity and clinical care. BMJ 2001;323:685-8.

22 Speiser $\mathrm{P}$, Rudolf M, Anhalt $\mathrm{H}$, Camacho-Hubner C, Chiarelli F, Eliakim A, et al. Childhood obesity. J Clin Endocrinol Metab 2005;90:1871-87.

23 Reilly J, Armstrong J, Dorosty A, Emmett P, Ness A, Rogers I, et al. Early life risk factors for obesity in childhood: cohort study. BMJ 2005;330:1357.

24 Niederer I, Kriemler S, Zahner L, Bürgi F, Ebenegger V, Hartmann T, et al. Influence of a lifestyle intervention in preschool children on physiological and psychological parameters (Ballabeina): study design of a cluster randomized controlled trial. BMC Public Health 2009;9:94.

25 Ebenegger V, Marques-Vidal PM, Nydegger A, Laimbacher J, Niederer I, Burgi F, et al. Independent contribution of parental migrant status and educational level to adiposity and Independent contribution of parental migrant status and educational

26 Urquia ML, Glazier RH, Blondel B, Zeitlin J, Gissler M, Macfarlane A, et al. International migration and adverse birth outcomes: role of ethnicity, region of origin and destination. $J$ Epidemiol Community Health 2010;64:243-51.

27 Swiss Society for Nutrition. Nutrition disk. Recommendations for healthy and tasty eating and drinking for children. 2011. www.sge-ssn.ch/fileadmin/pdf/600-medien_presse/40bilder/Ernaehrungsscheibe/Ernaehrungsscheibe englisch.pdf.

28 Health Promotion Switzerland. Kidz-Box. 25 Spiele und Tipps für Freude bei Bewegung und Ernährung. 2011. www.gesundheitsfoerderung.ch/pages/Gesundes_Koerpergewicht/ Tipps_Tools/kidzbox.php.

29 Leger LA, Mercier D, Gadoury C, Lambert J. The multistage 20 metre shuttle run test for aerobic fitness. J Sports Sci 1988;6:93-101.

30 Cole TJ, Bellizzi MC, Flegal KM, Dietz WH. Establishing a standard definition for child overweight and obesity worldwide: international survey. BMJ 2000;320:1240-3.

31 Schaefer F, Georgi M, Zieger A, Scharer K. Usefulness of bioelectric impedance and skinfold measurements in predicting fat-free mass derived from total body potassium in children. Pediatr Res 1994;35:617-24.

32 Lohman TG, Roche AF, Martorell R. Anthropometric standardization reference manual. Human Kinetics Books, 1988. 


\section{What is already known on this topic}

Obesity and low fitness are disproportionally prevalent in migrant children

Prevention programmes in this particular multicultural population are scarce, mostly ineffective, and even non-existent in preschool children

As obesity is caused by several diverse lifestyle behaviours, there is a need to evaluate multidimensional interventions

\section{What this study adds}

A multidimensional culturally tailored lifestyle intervention programme improved fitness and body fat, but not BMI, in predominantly migrant young children

The preschool age is a critical period to start prevention studies

33 Kunz T. Weniger Unfälle durch Bewegung: mit Bewegungsspielen gegen Unfälle und Gesundheitsschäden bei Kindergartenkindern. [Fewer accidents through increased activity: exercises to prevent accidents and health problems in preschool children.] Verlag Karl Hofmann, 1993.

34 Vogt U. Die Motorik 3-bis 6jahriger Kinder: ihre Abhangigkeit vom biologischen Entwicklungsstand und sozialen Umweltfaktoren. [Motor skills in 3-6 year old children: their association with biological developmental stage and social environmental factors.] Verlag Karl Hofmann, 1978.

35 Malina RM, Bouchard C, Bar-Or O. Growth, maturation, and physical activity. 2nd ed. Human Kinetics Books, 2004

36 Kapteyn TS, Bles W, Njiokiktjien CJ, Kodde L, Massen CH, Mol JM. Standardization in platform stabilometry being a part of posturography. Agressologie 1983;24:321-6.

37 Trost SG, Pate RR, Freedson PS, Sallis JF, Taylor WC. Using objective physical activity measures with youth: how many days of monitoring are needed? Med Sci Sports Exerc 2000;32:426.

38 Baquet G, Stratton G, Van Praagh E, Berthoin S. Improving physical activity assessment in prepubertal children with high-frequency accelerometry monitoring: a methodological issue. Prev Med 2007;44:1437.

39 Ebenegger V, Marques-Vidal P, Barral J, Kriemler S, Puder JJ, Nydegger A. Eating habits of preschool children with high migrant status in Switzerland according to a new food frequency questionnaire. Nutr Res 2010;30:104-9.

40 Ainsworth B, Jacobs D, Leon A. Validity and reliability of self-reported physical activity status: the Lipid Research Clinics questionnaire. Med Sci Sports Exerc 1993;25:92-8.

41 Werner $\mathrm{H}$, Molinari L, Guyer $\mathrm{C}$, Jenni $\mathrm{O}$. Agreement rates between actigraphy, diary, and questionnaire for children's sleep patterns. Arch Pediatr Adolesc Med 2008;162:350-8.

42 Varni J, Limbers C, Burwinkle T. Parent proxy-report of their children's health-related quality of life: an analysis of 13,878 parents' reliability and validity across age subgroups using the PedsQL 4.0 Generic Core Scales. Health Qual Life Outcomes 2007;5:1-10.

43 Ettrich $\mathrm{K}$, Ettrich $\mathrm{C}$. Testmanual zum Konzentrations-Handlungsverfahren für Vorschulkinder. [Testing manual for concentration assessment in preschool children.] Hogrefe, 2006

44 Grob A, Meyer CS, Hagmann-von Arx P. Intelligence and development scales (IDS). Hans Huber, 2009.

45 Taylor AW, Winefield H, Kettler L, Roberts R, Gill TK. A population study of 5 to 15 year olds: full time maternal employment not associated with high BMI. The importance of screen-based activity, reading for pleasure and sleep duration in children's BMI. Matern Child Health J 2011 Apr 20 [epub ahead of print].
46 Van Sluijs EM, McMinn AM, Griffin SJ. Effectiveness of interventions to promote physical activity in children and adolescents: systematic review of controlled trials. BMJ 2007;335:703.

47 Green DJ, Cable T. Physical activity to prevent obesity in young children: BMI in the BMJ. BMJ 2006;333:1171.

48 Mattocks C, Leary S, Ness A, Deere K, Saunders J, Kirkby J, et al. Intraindividual variation of objectively measured physical activity in children. Med Sci Sports Exerc 2007:39:622-9.

49 Ekelund U, Yngve A, Sjostrom M, Westerterp K. Field evaluation of the Computer Science and Application's Inc. Activity monitor during running and skating training in adolescent athletes. Int J Sports Med 2000;21:586-92.

50 Connelly JB, Duaso MJ, Butler G. A systematic review of controlled trials of interventions to prevent childhood obesity and overweight: a realistic synthesis of the evidence. Public Health 2007;121:510-7.

51 Blair SN, Kohl HW 3rd, Barlow CE, Paffenbarger RS Jr, Gibbons LW, Macera CA. Changes in physical fitness and all-cause mortality. A prospective study of healthy and unhealthy men. JAMA 1995;273:1093-8.

52 Lee CD, Blair SN, Jackson AS. Cardiorespiratory fitness, body composition, and all-cause and cardiovascular disease mortality in men. Am J Clin Nutr 1999;69:373-80.

53 Van Saase JL, Noteboom WM, Vandenbroucke JP. Longevity of men capable of prolonged vigorous physical exercise: a 32 year follow up of 2259 participants in the Dutch eleven cities ice skating tour. BMJ 1990;301:1409-11.

54 Andersen L, Harro M, Sardinha L, Froberg K, Ekelund U, Brage S, et al. Physical activity and clustered cardiovascular risk in children: a cross-sectional study (the European Youth Heart Study). Lancet 2006;368:299-304.

55 Lopes VP, Rodrigues LP, Maia JA, Malina RM. Motor coordination as predictor of physical activity in childhood. Scand J Med Sci Sports 2010;21:663-9.

56 Beaglehole R, Bonita R, Horton R, Adams C, Alleyne G, Asaria P, et al. Priority actions for the non-communicable disease crisis. Lancet 2011;377:1438-47.

Accepted: 07 September 2011

\section{Cite this as: BMJ 2011:343:d6195}

This is an open-access article distributed under the terms of the Creative Commons Attribution Non-commercial License, which permits use, distribution, and reproduction in any medium, provided the original work is properly cited, the use is non commercial and is otherwise in compliance with the license. See: http://creativecommons.org/licenses/bync/2.0/ and http://creativecommons.org/licenses/by-nc/2.0/legalcode. 


\section{Tables}

Table 1| Baseline characteristics of preschool children reported by parents according to intervention group (multidimensional lifestyle intervention) or control. Values are numbers (percentages) unless stated otherwise

\begin{tabular}{|c|c|c|c|}
\hline & Total $(n=652)$ & Intervention $(n=342)$ & Control $(n=310)$ \\
\hline Girls & $326(50)$ & $167(49)$ & $159(51)$ \\
\hline Mean (SD) age (years) & $5.2(0.6)$ & $5.2(0.6)$ & $5.2(0.6)$ \\
\hline French $v$ German part of Switzerland: & $334(51)$ & $176(51)$ & $158(51)$ \\
\hline \multicolumn{4}{|l|}{ Parental low educational level $(n=567)^{\star}$ : } \\
\hline Neither parent & $351(62)$ & $195(65)$ & $156(59)$ \\
\hline One parent & $121(21)$ & $65(21)$ & $56(21)$ \\
\hline Both parents & $95(17)$ & $42(14)$ & $53(20)$ \\
\hline Mainly speak foreign language at home $(\mathrm{n}=600)+$ : & $237(40)$ & $120(38)$ & $117(42)$ \\
\hline \multicolumn{4}{|l|}{ Parental migrant status $(n=601) \ddagger:$} \\
\hline Neither parent & $167(28)$ & $100(31)$ & $67(24)$ \\
\hline One parent & $147(24)$ & $72(22)$ & $75(27)$ \\
\hline Both parents & $287(48)$ & $151(47)$ & $136(49)$ \\
\hline \multicolumn{4}{|l|}{ Most common migrant regions $(n=370) \S$ : } \\
\hline Former Yugoslavia & $91(25)$ & $53(28)$ & $38(21)$ \\
\hline Portugal & $62(17)$ & $36(19)$ & $26(15)$ \\
\hline Rest of Europeף & $115(31)$ & $51(27)$ & $64(36)$ \\
\hline Africa & $45(12)$ & $23(12)$ & $22(12)$ \\
\hline Rest of world** & $57(15)$ & $28(14)$ & $29(16)$ \\
\hline
\end{tabular}

*Maximum of nine years' education.

†Any language other than German or French.

‡Born outside Switzerland.

$\S$ According to country of birth of father. Analogous numbers obtained for mother.

IPredominantly Mediterranean and Eastern Europe.

${ }^{\star *}$ Predominantly Asia, Middle East, and South America. 
Table 2| Adiposity and physical fitness outcomes in preschool children according to intervention group (multidimensional lifestyle intervention) and control group. Values are unadjusted means (SD) unless stated otherwise ${ }^{\star}$

\begin{tabular}{|c|c|c|c|c|c|c|c|}
\hline & \multicolumn{2}{|c|}{ Baseline } & \multicolumn{2}{|c|}{ After intervention } & \multicolumn{3}{|c|}{ Effect estimate } \\
\hline & $\begin{array}{l}\text { Intervention } \\
\quad(n=342)\end{array}$ & $\begin{array}{l}\text { Control } \\
(n=310)\end{array}$ & $\begin{array}{l}\text { Intervention } \\
\quad(n=333)\end{array}$ & Control ( $n=292)$ & Estimate† $(95 \% \mathrm{Cl})$ & $P$ value & ICC \\
\hline \multicolumn{8}{|l|}{ Physical fitness } \\
\hline $\begin{array}{l}\text { Aerobic fitness } \\
\text { (shuttle run, stages) }\end{array}$ & $2.9(1.3)$ & $2.9(1.4)$ & $4.6(1.7)$ & $4.3(1.7)$ & 0.32 (0.07 to 0.57$)$ & 0.01 & 0.07 \\
\hline $\begin{array}{l}\text { Agility (obstacle } \\
\text { course, seconds) }\end{array}$ & $19.4(4.6)$ & $19.3(4.4)$ & $16.2(2.8)$ & $16.7(3.2)$ & $\begin{array}{c}-0.54(-0.90 \text { to } \\
-0.17)\end{array}$ & 0.004 & $<0.01$ \\
\hline $\begin{array}{l}\text { Dynamic balance } \\
\text { (balance beam, } \\
\text { steps) }\end{array}$ & $2.4(1.6)$ & $2.3(1.7)$ & $3.1(2.2)$ & $2.9(2.0)$ & $0.2(-0.21$ to 0.60$)$ & 0.35 & 0.05 \\
\hline $\begin{array}{l}\text { Static balance } \\
\text { (balance platform, } \\
\text { total length, } \mathrm{mm} \text { ) }\end{array}$ & 941 (925) & $953(226)$ & $875(137)$ & $857(128)$ & $19.4(-9.1$ to 48.0$)$ & 0.18 & 0.10 \\
\hline \multicolumn{8}{|l|}{ Adiposity } \\
\hline BMI & $15.6(1.4)$ & $15.8(1.6)$ & $15.7(1.5)$ & $15.8(1.7)$ & $\begin{array}{c}-0.07(-0.19 \text { to } \\
0.06)\end{array}$ & 0.31 & 0.05 \\
\hline Percentage body fatł & $23.7(6.3)$ & $23.6(6.8)$ & $23.2(6.2)$ & $24.1(6.7)$ & $\begin{array}{c}-1.1(-2.02 \text { to } \\
-0.20)\end{array}$ & 0.02 & 0.18 \\
\hline $\begin{array}{l}\text { Sum of four skinfolds } \\
(\mathrm{mm})\end{array}$ & $27.3(8.1)$ & $26.6(9.2)$ & $25.7(7.5)$ & $28.4(11.1)$ & $\begin{array}{c}-2.78(-4.35 \text { to } \\
-1.2)\end{array}$ & 0.001 & 0.28 \\
\hline $\begin{array}{l}\text { Waist circumference } \\
(\mathrm{cm})\end{array}$ & $52.8(4.2)$ & $52.8(4.3)$ & $53.3(4.1)$ & $54.3(4.9)$ & $-1.0(-1.6$ to -0.42$)$ & 0.001 & 0.12 \\
\hline $\begin{array}{l}\% \text { Overweight (BMI } \\
\geq 90 \text { th centile)§ }\end{array}$ & 10.5 & 13.0 & 11.0 & 14.9 & 0.65 (0.32 to 1.32$)$ & 0.23 & $<0.01$ \\
\hline
\end{tabular}

ICC=intercluster correlation.

*9 children in intervention group and 18 in control group moved away after baseline testing (for more details see figure 2).

†For quantitative outcome variables, effect estimate describes difference between mean change in intervention group and mean change in control group, adjusted for baseline values of age, sex, and language region and for cluster factor preschool class (that is, unit of randomisation). For binary outcome variable (\% with $\mathrm{BMI} \geq 90$ th centile), effect estimate obtained from logistic regression models with same adjustments and expressed as odds ratio.

‡Bioelectrical impedance analysis.

§Cut off from International Obesity Task Force (IOTF). 
Table 3| Outcomes in cognitive abilities, quality of life, and lifestyle characteristics in preschool children according to intervention group (multidimensional lifestyle intervention). Values are unadjusted means (SD) unless stated otherwise*

\begin{tabular}{|c|c|c|c|c|c|c|c|}
\hline & \multicolumn{2}{|c|}{ Baseline } & \multicolumn{2}{|c|}{ After intervention } & \multicolumn{3}{|c|}{ Effect estimate } \\
\hline & $\begin{array}{l}\text { Intervention } \\
\qquad(n=342)\end{array}$ & $\begin{array}{l}\text { Control } \\
(n=310)\end{array}$ & $\begin{array}{l}\text { Intervention } \\
\qquad(n=333)\end{array}$ & $\begin{array}{l}\text { Control } \\
(n=292)\end{array}$ & $\begin{array}{c}\text { Estimate }(95 \% \\
\text { Cl) } \dagger\end{array}$ & $P$ value & ICC \\
\hline \multicolumn{8}{|c|}{ Cognitive abilities and quality of life } \\
\hline $\begin{array}{l}\text { Attention (KHV-VK, } \\
\text { duration in min) }\end{array}$ & $5.9(1.9)$ & $5.9(1.6)$ & $5.5(1.5)$ & $5.6(1.6)$ & $\begin{array}{c}-4.0(-27.0 \text { to } \\
19.1)\end{array}$ & 0.98 & 0.07 \\
\hline $\begin{array}{l}\text { Attention (KHV-VK, } \\
\text { correct cards) }\end{array}$ & $29.2(10.4)$ & $28.5(11.0)$ & $34.8(5.8)$ & $34.7(5.6)$ & $\begin{array}{c}0.05(-0.89 \text { to } \\
0.99)\end{array}$ & 0.87 & 0.03 \\
\hline $\begin{array}{l}\text { Spatial working } \\
\text { memory (IDS) }\end{array}$ & $3.7(2.0)$ & $3.6(2.0)$ & $4.8(1.7)$ & $4.6(1.7)$ & $\begin{array}{c}0.11(-0.31 \text { to } \\
0.54)\end{array}$ & 0.58 & 0.03 \\
\hline $\begin{array}{l}\text { Quality of life } \\
\text { (PedsQL, total } \\
\text { score) }\end{array}$ & $82.5(11.0)$ & $82.1(10.8)$ & $81.5(11.6)$ & $80.3(10.4)$ & $1(-0.57$ to 3.1$)$ & 0.17 & 0.02 \\
\hline \multicolumn{8}{|c|}{ Lifestyle characteristics } \\
\hline $\begin{array}{l}\text { Total physical } \\
\text { activity (cpm) }\end{array}$ & $724(166)$ & $729(165)$ & $817(186)$ & $820(215)$ & $\begin{array}{c}-12.3(-51.5 \text { to } \\
26.9)\end{array}$ & 0.54 & 0.05 \\
\hline $\begin{array}{l}\text { Media use (TV, } \\
\text { video and computer } \\
\text { games, } \min / \text { day) }\end{array}$ & $65.6(60.0)$ & $69.1(63.1)$ & $64.9(53.0)$ & $81.7(74.5)$ & $\begin{array}{c}-13.4(-25.0 \text { to } \\
-1.7)\end{array}$ & 0.03 & 0.06 \\
\hline $\begin{array}{l}\text { Sleep duration } \\
\text { (h/day) }\end{array}$ & $10.9(0.6)$ & $10.9(0.6)$ & $10.9(0.6)$ & $10.8(0.6)$ & $\begin{array}{c}0.002(-0.09 \text { to } \\
0.1)\end{array}$ & 0.97 & 0.03 \\
\hline Active children (\%)‡ & $44.8 \%$ & $49.0 \%$ & $53.1 \%$ & $43.7 \%$ & 1.7 (1.1 to 2.6$)$ & 0.01 & $<0.01$ \\
\hline Healthy eaters (\%)§ & $26.4 \%$ & $21.4 \%$ & $24.3 \%$ & $12.4 \%$ & 1.9 (1.02 to 3.6$)$ & 0.04 & $<0.01$ \\
\hline
\end{tabular}

$\mathrm{ICC}=$ intercluster correlation ; $\mathrm{cpm}=$ counts per minute. KHV-VK=Konzentrations-Handlungsverfahren für Vorschulkinder [concentration test for preschoolers]. IDS=Intelligence and Development Scales. PedsQL=Pediatric Quality of Life Inventory.

${ }^{*} 9$ children in intervention group and 18 in control group moved away after baseline testing (for more details see figure 2).

†For quantitative outcome variables, effect estimate describes difference between mean change in intervention group and mean change in control group, adjusted for baseline values of age, sex, and language region and for cluster factor preschool class (that is, unit of randomisation). For binary outcome variables (active children and healthy eaters), effect estimates obtained from logistic regression models with same adjustments and expressed as odds ratios. ‡Reported by parents to be more active than other children of same age and sex (Lipid Research Clinics questionnaire). $\S$ Correspond to healthiest quarter of recommendations of Swiss Society of Nutrition (food frequency questionnaire). 


\section{Figures}

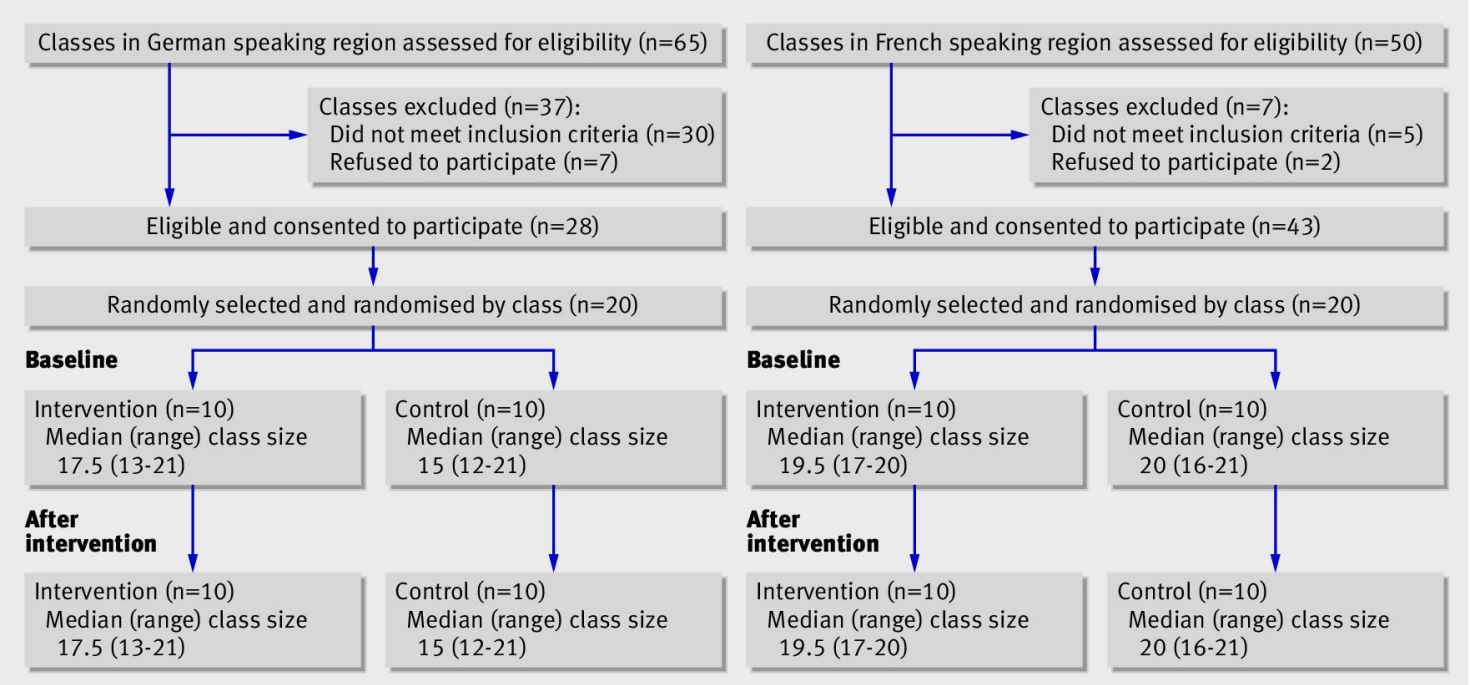

Fig 1 Trial profile of clusters. Inclusion criteria were $>40 \%$ prevalence of migrant children and no participation in any other prevention project. Reasons for refusals were lack of interest or time (of director or teacher) or health problems of teacher

\begin{tabular}{|c|c|c|c|c|c|c|c|}
\hline \multicolumn{8}{|c|}{ Invited to participate $(n=727)$} \\
\hline & & & & & & & \\
\hline \multicolumn{8}{|c|}{ Randomisation } \\
\hline & & & & & \multicolumn{3}{|c|}{ Withdrawal by parents $(n=72)$} \\
\hline \multicolumn{8}{|c|}{$\begin{array}{l}\text { Consented }(n=655) \\
\text { Present for baseline BMI or aerobic fitness }(n=652)\end{array}$} \\
\hline & \multicolumn{4}{|c|}{$\downarrow$} \\
\hline \multicolumn{4}{|c|}{$\begin{array}{l}\text { Intervention }(n=342) \\
\text { Moved away after baseline testing }(n=8)\end{array}$} & \multicolumn{4}{|c|}{$\begin{array}{l}\qquad \text { Control }(n=310) \\
\text { Moved away after baseline testing }(n=18)\end{array}$} \\
\hline Baseline & $\begin{array}{l}\text { After } \\
\text { intervention }\end{array}$ & Both & \multicolumn{2}{|c|}{ Primary outcomes } & Baseline & $\begin{array}{c}\text { After } \\
\text { intervention }\end{array}$ & Both \\
\hline 342 & 336 & 335 & \multicolumn{2}{|c|}{$\mathrm{BMI}^{*}$} & 307 & 296 & 291 \\
\hline 323 & 319 & 302 & \multicolumn{2}{|c|}{ Aerobic fitness } & 293 & 287 & 269 \\
\hline \multicolumn{8}{|c|}{ Secondary outcomes } \\
\hline 322 & 327 & 309 & \multicolumn{2}{|c|}{ Sum of four skinfolds } & 293 & 279 & 263 \\
\hline 314 & 327 & 301 & \multicolumn{2}{|c|}{ Percentage body fat $\dagger$} & 288 & 278 & 259 \\
\hline 327 & 329 & 315 & \multicolumn{2}{|c|}{ Waist circumference } & 300 & 287 & 277 \\
\hline 287 & 264 & 236 & \multicolumn{2}{|c|}{ Physical activity $\ddagger$} & 255 & 220 & 185 \\
\hline 322 & 326 & 309 & \multicolumn{2}{|c|}{ Cognitive abilities§ } & 294 & 280 & 264 \\
\hline 318 & 300 & 286 & \multicolumn{2}{|c|}{ General health questionnaire $\|^{\star \star}$} & 277 & 265 & 245 \\
\hline 235 & 222 & 180 & \multicolumn{2}{|c|}{ Eating habits ${ }^{* *+\dagger}$} & 192 & 198 & 141 \\
\hline
\end{tabular}

Fig 2 Trial profile of participants. *BMl at follow-up also measured in four control and one intervention child who had moved away; †bioelectrical impedance analysis; łmeasured by accelerometry; §attention and spatial working memory; Ireported physical activity, sleep duration, and media use; **assessed with parental questionnaires; ††completed all questions related to five recommendations of Swiss Society of Nutrition (used to calculate sum score). One child with cerebral palsy was excluded from fitness testing 